\title{
Study on Knowledge Sharing Mechanism of University Teachers in Information Age
}

\author{
Xiaohui Yang ${ }^{1, \text { a }}$ \\ ${ }^{1}$ Network and Information Management Division, Chifeng University, Inner Mongolia, 024000, \\ China \\ aemail: interne1669@aliyun.com
}

\begin{abstract}
Keywords: Knowledge Sharing; Sharing Mechanism; University Teachers; Knowledge Management
\end{abstract}

\begin{abstract}
How to realize effective knowledge sharing of university teachers is mainly discussed in the paper. The obstacles of university teachers' knowledge sharing mainly lie in the cultural, institutional and technical aspects. The effective ways to build university teachers' knowledge sharing mechanism, such as perfecting incentive mechanism, constructing knowledge sharing platform and cultivating knowledge sharing culture are given in the paper.
\end{abstract}

\section{Introduction}

In recent years, knowledge sharing has been identified as a major focus area for knowledge management. Efforts are made with a view to identify the most effective ways to share knowledge, as a step towards improving organizational performance. Various factors have been identified as impediments for knowledge sharing, including inadequate organizational structures, unfriendly organizational sharing cultures, and insufficient technological support in this striving. At the same time, with the higher education becoming international and diversified, knowledge is the core competitiveness of colleges and universities, and is also the core resources to create value which is to improve the operational efficiency. As in the other knowledge-intensive organizations, knowledge management will improve the whole performance, innovation and comprehensive strength of colleges and universities. Knowledge sharing is a very important part in the process of knowledge management. Knowledge sharing can be to maximize the knowledge to be master and use, and improve the efficiency in the use of knowledge as well as to reduce costs. Knowledge sharing can also prevent some valuable knowledge losing their value as a result of no-sharing. Knowledge sharing can also help to realize organization value, promote members' level of satisfaction.

This paper proposes several ways of approaching knowledge sharing in the context of information and communication technology development.

\section{KNOWLEDGE MANAGEMENT AND KNOWLEDGE SHARING}

Knowledge management is a management theory which emerged in the 1990s. It seeks to understand the way in which knowledge is created, used and shared within organizations. Knowledge Management (KM) comprises a range of practices used by organizations to identify, create, represent, and distribute knowledge for reuse, awareness and learning. It has been an established discipline since 1995 with a body of university courses and both professional and academic journals dedicated to it [1]. Most large companies have resources dedicated to Knowledge Management, often as a part of "Information Technology" or "Human Resource Management" departments, and sometimes reporting directly to the head of the organization [2]. As effectively managing information is a must in any business, Knowledge Management is a multi-billion dollar global market.

In the field of education, knowledge management is a collection of all kinds of canonical knowledge, which transformed from various instructional resources and connected as net-structure. 
At the same time, knowledge management in educational field provides open management to knowledge in order to realize the production, utilization and share of knowledge [3]. Tom Finneran defines the ideal knowledge management Infrastructure(Fig.1) would take advantage of existing knowledge[4], stimulate the development of new knowledge and ideas, acquire knowledge directly and painlessly, automatically classify and interrelate knowledge, make knowledge globally accessible so that the right knowledge could be obtained and effectively utilized by any Knowledge worker who needs it[5].
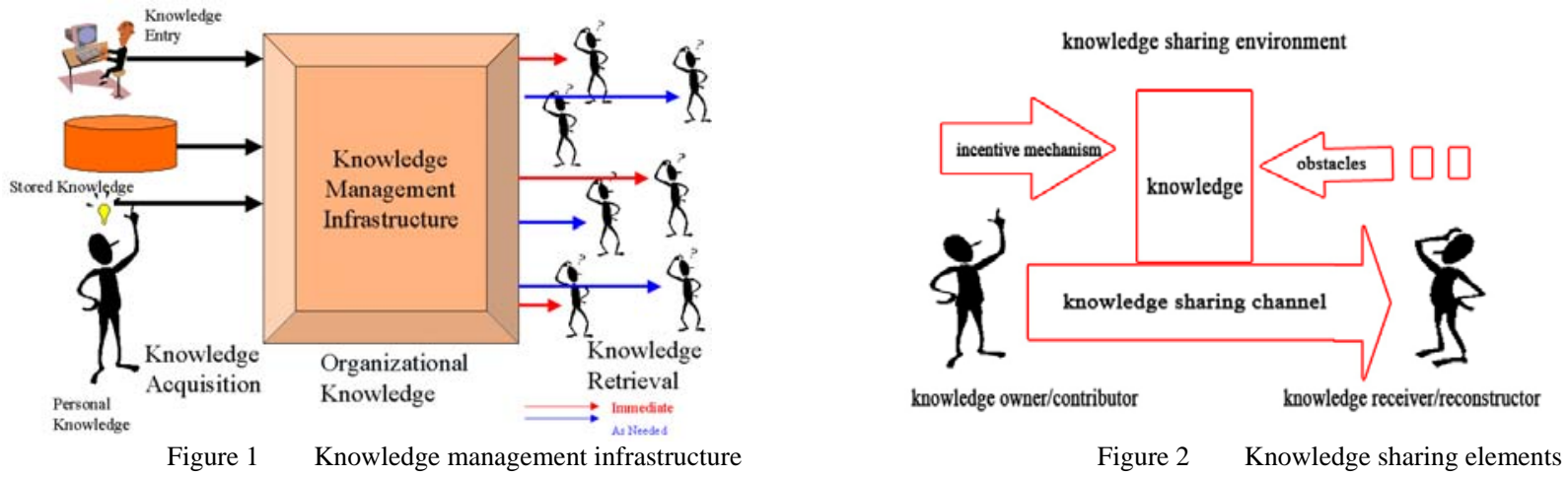

Summarizing some scholars' viewpoint, knowledge management includes four parts, namely knowledge acquisition, knowledge storage, knowledge sharing and knowledge creation. Knowledge sharing is the core of knowledge management, and also one of the difficulties of the knowledge management. Knowledge sharing refers to the individual knowledge, and the organization knowledge is shared with other members in the organization through each sharing methods, simultaneously, it realizes organization's knowledge increment through the knowledge innovation. Therefore, the knowledge sharing should be understood from three level considerations: the knowledge sharing object--knowledge content, knowledge sharing method--knowledge network, the conference and the team studies, the main body of knowledge sharing--team and organization[6].

Knowledge is one kind of scarce resources, it belongs to intangible asset of the knowledge main body, but this kind of property does not have the loss, that is, when a person provides the knowledge to another person, the providers will not therefore cause their own knowledge to reduce. For all that, it is not easy to realize effective knowledge sharing within organizations. Current theories provide only fragmented insights into the origination of knowledge sharing, and thus offer limited guidance for knowledge management practices in colleges and universities. The contribution of this paper is to give some available suggestions for the practice of university teachers' knowledge sharing based-on obstacles analyzing under the background of information.

\section{ANALYSIS ON OBSTACLES OF KNOWLEDGE SHARING OF UNIVERSITY TEACHERS}

One of the challenges of knowledge management is that of getting people to share their knowledge. The exchange of information is a vital component of the knowledge management process. In many organizations, the need for active knowledge sharing is accepted, but all too often in practice the belief exists that waving a sophisticated and expensive information technology system is all that is needed for good knowledge management. Knowledge sharing is something else than but related to communication and to information distribution [7]. Knowledge sharing presumes a relation between at least two parties, one that possesses knowledge and the other that acquires knowledge. The first party should communicate its knowledge, consciously and willingly or not, in some form or other (either by acts, by speech, or in writing, etc.). The other party should be able to perceive these expressions of knowledge, and make sense of them (by imitating the acts, by listening, by reading the book, etc.). The resemblances between knowledge sharing and information distribution, however, gave us the basis to formulate the premises for the proposed methods.

Despite the growing significance of knowledge sharing practices for universities' competitiveness, several barriers make it difficult for knowledge management to achieve the goals and deliver a positive result. Some of the common reasons people and, ultimately, organizations, are 
skeptical in sharing knowledge are: the reign of the principle "knowledge is power", not realizing how useful particular knowledge is to others, lack of trust, lack of time, individualism, poor means of knowledge capture, inadequate technology, internal competition and top-down decision making and others.

Based on this, the obstacles of university teachers' knowledge sharing can be summarily analyzed as following.

A. Cultural obstacles in knowledge sharing of university teachers

Organizational culture plays an important role in the knowledge sharing. Cultural barriers of knowledge sharing often manifested the lack of correct understanding on knowledge sharing, inoperative positive value concept and the choice of sharing behavior. Restriction of cultural environment is the biggest obstacle of knowledge sharing, such as the lack of mutual trust and equal exchange, not to encourage innovation etc.

On Colleges and Universities, the cultural barriers of knowledge sharing mainly refer to the lack of sharing consciousness and cooperative spirit. Due to the busy teaching work and heavy scientific research task, there is very little time to communication and exchange between teachers. The characteristic of teacher's job is relatively independent, and many outstanding teachers tend to stick to their own barony of business and academic instead of cooperation and interaction with others, which is the waste of resources.

The source of this bad sharing atmosphere lies in interest conflict and knowledge difference. On the one hand, the enormous function of knowledge sharing is to improve overall organizational knowledge level by sharing individual knowledge with other members in organization. People are often willing to do what's best for themselves, not to their own interests at the expense of compromise and sacrifice. On the other hand, the differences such as knowledge structure, knowledge understanding, thinking model, cognizing style and values between teachers result in the difficult to form a mutual benefit not only to accepter but also giver. When the transfer of knowledge is only one-way, the knowledge owners would not be willing to transfer their knowledge, can only be a lecture type preaching, and can't form a shared environment.

B. Institutional obstacles in knowledge sharing of university teachers

The existing organizational structure of most universities is the pyramid-like level management model [8]. In this mode, there are so many layers of management, which without question will affect the speed of information transfer. In this organizational structure, teachers often only work in specific smaller narrower range for the particularity and professionalism of the teaching and research. Therefore the faculty and staff often make their tasks and responsibilities one-sided while ignoring the organization's objectives and responsibilities from the perspective of the universities. There are hierarchical gaps among staffs or departments in internal communication due to level management. The level management and work difference hinder direct contact and exchange. Channels for knowledge sharing is not smooth inevitably affect the realization of the knowledge-sharing. At the same time, the institutional and systemic adverse factors, resulting in the lack of enthusiasm of the faculty and staff to knowledge-sharing. The linear organizational structure of universities has also hindered the implementation of knowledge sharing.

C. Technological obstacles in knowledge sharing of university teachers

Although the cultural environment is crucial factor for knowledge sharing of university teachers, the support of information technology is essential. If lacking necessary technical support, knowledge sharing will be difficult to play its due effect, eventually become a mere formality and to be empty. Role and motivation of technology as a pillar in knowledge management process presents an encouraging picture for organizations vying knowledge sharing. Modern information and telecommunication technology is available to support knowledge sharing across time and distance barriers improving access to information about knowledge [9]. However, universities investing in this type of technology often face difficulties in encouraging their teachers to use the systems to share their ideas. This brings us to a crucial question on knowledge management and sharing in universities: What can technology offer in knowledge sharing?

Looking at information and communication technology from the perspective of knowledge 
sharing, however, cannot by itself solve all problems including such as lack of mutual trust among staffs, envy and fear for others' successful etc. But it is undoubtedly that the appropriate information and network technology support is a good catalyst for knowledge sharing.

\section{THE EFFECTIVE WAYS TO REALIZE UNIVERSITY TEACHERS' KNOWLEDGE SHARING}

Knowledge sharing is that some unique knowledge owned by individuals transforms one owned by other members of the team, or the team's overall knowledge by some knowledge transfer ways such as the identification, acquisition, analysis, absorption, utilization of knowledge in the management and incentives of a team or organization. To realize effective knowledge sharing in colleges and universities needs to match the following three conditions: Firstly, there are enough and valuable knowledge that can be shared within the colleges and universities. That is, the teacher who contributes his knowledge (tacit and explicit) to others needs higher level of expertise, good communication skills and knowledge sharing willingness. Secondly, receiver of knowledge sharing has the strong willing to accept the knowledge from other members, and has enough capacity to receive knowledge or information. Thirdly, there are appropriate way and suitable environment of knowledge sharing in universities. Only when the above three basic elements is up to scratch, knowledge sharing of college teachers is possible (Fig. 2). According to previous obstacles analysis, some available suggestions to form effective knowledge-sharing mechanisms in colleges and universities can be proposed in order to satisfying the above three conditions, and then the effective knowledge sharing of university teachers can be realized.

A. Improving the incentive mechanism of university teachers' knowledge sharing

Michael Lebocuf, a famous American management expert, believes that you should encourage and reward what you want. Develop incentive system to make all knowledge-sharing efforts have been recognized, and to find a way to strengthen and reward knowledge sharing, and to promote teachers who are willing to learn, teach and share knowledge, and to punish those who are unwilling to do so. Sharing which is always voluntary happen to be the challenge in developing an environment where people both want to share what they know and make use of what others know. "To convince experts to share their knowledge, organization needs to make them aware of why it is important to share knowledge [10]." This way will make them feel that they are important and be willing to share their knowledge. To establish the principle of reasonable return, which can be moral and material compensation for teachers who has make achievements in promoting knowledge sharing, is necessary in order to perfect the knowledge-sharing incentives. The satisfaction of self-actualization is generally embodied in two aspects, sense of competence and sense of achievements.

B. Creating an Available Knowledge Sharing Platform

The rapid development of information technology and Internet has greatly changed the style of people's production and life. Computer plays an important role in the creating, processing, distribution and transmission of information. Therefore, universities should provide network with intact infrastructure for staff to acquire and exchange relative knowledge, and establish perfect online platform to help teachers finishing knowledge acquisition, knowledge classification, knowledge retrieval and knowledge exchange.

The knowledge sharing platform should try to broaden the knowledge-sharing channels by ways such as on-line discussion forum, blog, Wiki, e-mail, information stations, to make the knowledge-sharing available. But the teachers must firstly master the basic knowledge and basic skills to access on-line resource, know how to operate the browser, reader, player, search engines, download tools. The participator takes part in a wide range of subject, and the skills of querying and browsing the information are improved, but also skills of exchanging the information are enhanced. C. Fostering Friendly Knowledge Sharing Culture

The organization culture is a shared value system within the organization, which largely affects the behavior of members. Holsapple and other researchers think that the level of knowledge sharing requires tolerance and lenience between members, and needs to establish friendly and close 
cooperation relations, and has also benefited from the recognition of organizational integration [11]. For knowledge sharing to work, universities first have to have a culture that open and accept sharing. Studies by De Long and Liam show that culture influence knowledge sharing by as much as $80 \%$.Consequently, to effectively develop organization knowledge sharing culture, there need to be change in the culture of the organization strategy, structure, support mechanism, management development, communication, trust, motivation and learning. These approaches are all based on the fundamental premise that it is management's role to do the motivating and foster teachers toward knowledge sharing culture.

\section{Conclusion}

The university teachers' knowledge sharing is the flowing and commutative process of knowledge, which is a kind of adventurous exchange behavior. Knowledge sharing research involves theories of several disciplines such as management, psychology, philosophy and sociology. It is very difficult to formulate clearly the effective ways to realize university teachers' knowledge sharing. But viewed as a whole, the suggestions given above, that is, improving the incentive mechanism of knowledge sharing, creating an available knowledge sharing platform and fostering friendly knowledge sharing culture can be available methods. By using these methods, colleges and universities can better mitigate the risks and challenges in teachers' knowledge sharing and increase the chances of a successful solution in university teachers' knowledge sharing.

\section{References}

[1] Stankosky, M., "Creating the Discipline of Knowledge Management: The Latest in University Research”, Butterworth-Heinemann, ISBN 0-7506-7878-X. 2004.

[2] M. Alavi and D. E. Leidner, "Knowledge management and knowledge management systems conceptual foundations and research issues,” MIS Quarterly, vol. 25, no. 1, 2001.

[3] Kekang He, Wenguang Li, "Educational Technology”, The press of Beijing Normal University, Beijing, 2002.

[4] Tom Finneran, “A Component-Based Knowledge Management System”, The Data Administration Newsletter, June 1, 1999.

[5] Xiaohui Yang, “Improving Teachers’ Knowledge Management with Blog Platform” , International Workshop on Education Technology and Training Content, IEEE Computer Society, Feb. ,2009.

[6] Wei Leng, "Study on Knowledge Sharing Mechanism in Open Virtual Learning Communities”, International Journal of Business and Management, Vol. 4 No. 1, Jan., 2009.

[7] Hendriks, Paul, "Research Article: Why Share Knowledge? The Influence of ICT on the Motivation for Knowledge Sharing”, Knowledge and Process Management, Volume 6 Number 2 , 1999.

[8] Fred.C.Lunenburg, Allan.C.Onistein. “Theory and Practice of Educatioanal Management” , translated by Sun Zhijun and others, China Light Industry Publishing, Beijing, 2003.

[9] Thierauf, Robert J., Knowledge Management Systems for Business, ISBN 1-56720-218-7, Quorum Books, Westport, CT. 1999.

[10] Frances Horibe. Managing Knowledge Workers: New Skills and Attitudes to Unlock the Intellectual Capital in Your Organization. Canada: John Wiley \& Sons Canada Limited. 1999. [11] Holsapple C W, Joshi K D. An lnvestigation of Factors That Influence the Mnagaement of Knowledge in Ogrnaiaztion. Journal of strategic Information Systems, 2000. 